\title{
German Guideline for Idiopathic Pulmonary Fibrosis - Update on Pharmacological Therapies 2017
}

\section{S2k-Leitlinie Idiopathische Lungenfibrose - Update zur medikamentösen Therapie 2017}

Authors

Jürgen Behr ${ }^{1}$, Andreas Günther ${ }^{2}$, Francesco Bonella ${ }^{3}$, Klaus Geißler ${ }^{4}$, Dirk Koschel ${ }^{5}$, Michael Kreuter ${ }^{6}$, Antje Prasse ${ }^{7}$, Nicolas Schönfeld ${ }^{8}$, Helmut Sitter ${ }^{9}$, Joachim Müller-Quernheim ${ }^{10}$, Ulrich Costabel ${ }^{3}$

Institutions

1 Medizinische Klinik und Poliklinik V, Klinikum der Universität München (LMU) und Asklepios Fachkliniken München-Gauting, Comprehensive Pneumology Center, Mitglied des Deutschen Zentrums für Lungenforschung

2 Schwerpunkt Fibrosierende Lungenerkrankungen, Universitätsklinikum Gießen - Marburg, Standort Gießen, Justus-Liebig-Universität Gießen, sowie Agaplesion Pneumologische Klinik WaldhofElgershausen, University of Giessen Marburg Lung Center, Mitglied des Deutschen Zentrums für Lungenforschung

3 Schwerpunkt interstitielle und seltene Lungenkrankheiten, Ruhrlandklinik, Universitätsklinikum Essen

4 Patientenvertretung Lungenfibrose e.V., Essen

5 Abteilung Innere Medizin/Pneumologie, Fachkrankenhaus Coswig, Zentrum für Pneumologie, Allergologie, Beatmungsmedizin, Thoraxchirurgie

6 Zentrum für interstitielle und seltene Lungenerkrankungen, Pneumologie und Beatmungsmedizin, Thoraxklinik, Universitätsklinikum Heidelberg, Mitglied des Deutschen Zentrums für Lungenforschung

7 Klinik für Pneumologie, Medizinische Hochschule Hannover und Clinical Research Center Fraunhofer Institut ITEM, Mitglied des Deutschen Zentrums für Lungenforschung

8 Klinik für Pneumologie, Lungenklinik Heckeshorn, HELIOS Klinikum Emil von Behring, Berlin

9 Institut für Theoretische Chirurgie, Philipps-Universität Marburg

10 Klinik für Pneumologie, Department Innere Medizin, Medizinische Fakultät, Albert Ludwigs Universität, Freiburg

Bibliography

DOI https://doi.org/10.1055/s-0043-123035

Published online: 16.1.2018 | Pneumologie 2018; 72:

155-168

(c) Georg Thieme Verlag KG Stuttgart · New York ISSN 0934-8387
Corresponding author

Prof. Dr. med. Jürgen Behr, Asklepios Fachkliniken Gauting und Medizinische Klinik und Poliklinik V, Comprehensive Pneumology Center, Klinikum der Universität München, Marchioninistr. 15, 81377 München juergen.behr@med.uni-muenchen.de

\section{ABSTRACT}

Idiopathic pulmonary fibrosis (IPF) is a severe and often fatal disease with a median survival of $2-4$ years after diagnosis. Since the publication of the German IPF guideline in 2013 new treatment trials have been published, necessitating an update of the pharmacological therapy of IPF. Different from the previous guideline, the GRADE system was discarded and replaced by the Oxford evidence classification system which allows a more differentiated judgement. The following pharmacological therapies were rated not suitable for the treatment of IPF patients (recommendation A; evidence 1-b): triple therapy with prednisolone, azathioprine and acetyl-cysteine; imatinib; ambrisentan; bosentan; macitentan. A less clear but still negative recommendation (B, 1-b) was attributed to the treatment of IPF with the phosphodiesterase-5-inhibitor sildenafil and acetyl-cysteine monotherapy. In contrast to the international guideline antacid therapy as a general treatment for IPF was rated negative, based on conflicting results of recent analyses (recommendation C; evidence 4). An unanimous positive recommendation was granted for the antifibrotic drugs nintedanib and pirfenidone for the treatment of IPF (A, 1-a). For some open questions in the management of IPF patients for which firm evidence is lacking the guideline also offers recommendations based on expert consensus.

\section{ZUSAMMENFASSUNG}

Die idiopathische Lungenfibrose (idiopathische pulmonale Fibrose, IPF) ist eine schwerwiegende Lungenerkrankung, die häufig innerhalb von zwei bis vier Jahren nach Diagnosestellung zum Tod führt. Seit Veröffentlichung der deutschen IPF-Leitlinie im Jahr 2013 liegen neue Therapiestudien vor, die eine Neubewertung der Behandlungsstrategien er- 
fordern. Abweichend von der Vorgängerleitlinie wurde in der aktuellen Überarbeitung nicht mehr das GRADE-System sondern die Oxford Evidenzsystematik mit drei Empfehlungsgraden (A, B, C) verwendet, weil dieses System eine differenziertere Betrachtung erlaubt. Folgende Medikamente wurden mit dem Empfehlungsgrad A und dem Evidenzgrad 1-b als nicht geeignet für die Behandlung der IPF klassifiziert: Triple-Therapie aus Prednisolon, Azathioprin und Acetylcystein; Antikoagulation mit Vitamin-K-Antagonisten; Imatinib; Ambrisentan; Bosentan; Macitentan. Weniger eindeutig ist die negative Bewertung des Phosphodiesterase-5-Inhibitors Sildenafil und der Acetylcystein-
Monotherapie (Empfehlungsgrad B, Evidenzgrad 2-b). Eindeutig positiv fiel die Empfehlung für Nintedanib und Pirfenidon zur Behandlung von IPF-Patienten aus (Empfehlungsgrad A, Evidenzgrad 1-a). Mit Empfehlungsgrad C und Evidenzgrad 4 wurde der generelle Einsatz von Antazida zur Behandlung der IPF als nicht zu empfehlen bewertet, da die Datenlage widersprüchlich ist; hier weicht die deutsche Leitlinie auch am deutlichsten von der internationalen Leitlinie ab. Am Ende der Leitlinie wird aus Expertensicht zu offenen Fragen in der Therapie der IPF Stellung genommen, für die bisher keine ausreichende Evidenzbasis existiert.

\section{Guideline report}

\section{Scope of application and purpose}

This guideline for therapy of idiopathic lung fibrosis (idiopathic pulmonary fibrosis, IPF) is an update of the recommendations for pharmacological therapy of IPF of the S2K guideline for diagnostics and therapy of idiopathic lung fibrosis published in 2013 in the PNEUMOLOGIE journal [1].

Since the most recent publication of the guideline, there have been a relevant number of additional evidence-based trials to be considered, particularly in respect of pharmacological therapy of IPF. The extent of scientific findings has increased significantly so that this update is published as a supplement to the original guideline.

The topics of non-pharmacological therapy (e. g. lung transplantation, rehabilitation), palliative drug treatment of symptoms (e.g. cough, shortness of breath) and complications (e. g. pulmonary hypertension) are not discussed here.

This guideline addresses professional groups (physicians and non-physicians) which in the broadest sense may be involved in IPF treatment (e.g. physiotherapists, natural scientists, nurses, self-help groups and interested laypersons).

\section{Composition of the guideline group, participation of interest groups}

Prof. Dr. med. Jürgen Behr, Munich (lead)

Prof. Dr. med. Andreas Günther, Giessen

Prof. Dr. med. Ulrich Costabel, Essen

Prof. Dr. med. Joachim Müller-Quernheim, Freiburg

Dr. med. Nicolas Schönfeld, Berlin

Prof. Dr. med. Antje Prasse, Hannover

PD Dr. med. Dirk Koschel, Coswig

Prof. Dr. med. Michael Kreuter, Heidelberg

Dr. med. Francesco Bonella, Essen

Klaus Geißler, Bietigheim-Bissingen

PD Dr. med. Helmut Sitter, Marburg

To ensure the representative composition of the guideline group, the following professional groups and patient representatives were involved.

Medical associations:
- German Society of Internal Medicine (Deutsche Gesellschaft für Innere Medizin - DGIM) represented by J. Müller-Quernheim

- German Respiratory Society (Deutsche Gesellschaft für Pneumologie und Beatmungsmedizin - DGP) represented by J. Behr

Patient organizations:

- Pulmonary Fibrosis (Lungenfibrose e. V.) represented by K. Geißler

- Association of the Scientific Medical Societies in Germany (Arbeitsgemeinschaft der Wissenschaftlichen Fachgesellschaften - AWMF), facilitator: H. Sitter

\section{Methodology}

The entire development of this guideline was facilitated by AWMF (Association of the Scientific Medical Societies in Germany). Voting in the consensus conferences took place in accordance with the nominal group technique process, facilitated by PD. Dr. Helmut Sitter.

As this is an S2K guideline, the consensus process included the following elements:

Logical analysis, formal consensus building, evidence-basing, decision analysis ( $\triangleright$ Table 1 ). The rules for S2 guidelines state, that a solution has to be based on a clearly defined set of questions, and derived in several steps using conditional logic (if-then logic). For evidence-basing, clinical trials and metaanalyses are included as well. There was agreement to use three recommendation levels, A, B and C, as shown in > Table 2 and - Table 3. For recommendation level A (strong recommendation) the wording is "shall," for B (moderate recommendation) "should," and for C (weak recommendation) "may."

During the consenting process, diverging recommendation levels may also be adopted in justified circumstances. 
Table 1 Elements of the systematic development of the guideline.

Logic

Consensus

Evidence

Decision analysis

- Table 2 Allocation of recommendation levels to evidence levels.

Recommendation level: A, B, C

Evidence level

A1a, 1 b, 1c

B2a-c, 3a, 3b, 4

C4, 5

- Table 3 Trial forms, Oxford levels of evidence.

\begin{tabular}{|c|c|}
\hline Evidence level & Description \\
\hline $1 \mathrm{a}$ & $\begin{array}{l}\text { Evidence by systematic review of randomized } \\
\text { controlled trials (RCT) }\end{array}$ \\
\hline $1 b$ & Evidence by an appropriate planned RCT \\
\hline $1 c$ & All or none principle \\
\hline $2 a$ & $\begin{array}{l}\text { Evidence by systematic review of well-planned } \\
\text { cohort trials }\end{array}$ \\
\hline $2 b$ & $\begin{array}{l}\text { Evidence by a well-planned cohort trial/RCT of } \\
\text { moderate [poor] quality (e. g. }<80 \% \text { follow-up) }\end{array}$ \\
\hline $2 c$ & Evidence by outcome research trials \\
\hline $3 a$ & $\begin{array}{l}\text { Evidence by systematic review of well-planned } \\
\text { case-control studies }\end{array}$ \\
\hline $3 b$ & Evidence by a case-control study \\
\hline 4 & $\begin{array}{l}\text { Evidence by case series/cohorts and case- } \\
\text { control studies of moderate [poor] quality }\end{array}$ \\
\hline 5 & $\begin{array}{l}\text { Expert opinion without explicit critical appraisal, } \\
\text { or based on physiological models, laboratory } \\
\text { [bench] research or "first principles" }\end{array}$ \\
\hline
\end{tabular}

\section{Drafting of the guideline/consenting}

The first version of the guideline was drafted under the direction of the lead author, Jürgen Behr, and the authors of the individual chapters.

This version provided the basis for the consensus meeting held in Munich on December 16, 2016.

The meeting was attended by:

Prof. Dr. med. Jürgen Behr, Munich (lead)

Prof. Dr. med. Andreas Günther, Giessen

Prof. Dr. med. Ulrich Costabel, Essen

Dr. med. Nicolas Schönfeld, Berlin

Prof. Dr. med. Antje Prasse, Hanover
PD Dr. med. Dirk Koschel, Coswig

Prof. Dr. med. Michael Kreuter, Heidelberg

Dr. med. Francesco Bonella, Essen

Klaus Geißler, Bietigheim-Bissingen

PD Dr. med. Helmut Sitter, Marburg

Excused: Prof. Dr. med. Joachim Müller-Quernheim, Freiburg

\section{Literature Research}

The literature research was based on the international IPF guideline [2]. In addition, current literature up until 12/2016 was considered if it satisfied the criteria listed below or was deemed to be important. The following were defined as inclusion criteria:

German- or English-language publications, prospective or retrospective clinical trials, randomized controlled trials, controlled clinical trials, systematic reviews, meta-analyses, guidelines of the AWMF, the European and North American professional associations (practice guidelines, guidelines) in German or English. Exclusion criteria were defined as: original works not published in German or English, trials involving animal experimentation, letters from readers, case reports (case descriptions), expert opinions, reviews (review articles), which did not represent a systematic summary of the literature but provided only a general overview of the topic.

A total of 90 published papers were selected. Previously, the guideline group had decided to use the therapy update of the international IPF guideline from 2015 as the basis for updating the German IPF guideline from 2013. The appraisal of the literature was performed by two members of the guideline group, respectively, according to the Oxford Centre for Evidencebased Medicine Levels of Evidence (2001).

\section{External appraisal and adoption}

The guideline was discussed and adopted by the board members of the medical societies involved.

\section{Editorial independence}

\section{Funding of the Guideline}

The creation of the guideline and hosting of the consensus conference was exclusively funded by the German Respiratory Society (DGP).

\section{Disclosure and handling of potential conflicts of interest}

Potential conflicts of interest were documented using standardized forms of the AWMF. All the individuals involved provided the required responses. The information concerning the conflict of interest declarations were critically reviewed by two members of the steering committee (H.S. and J.B.). It was decided that conflicts of interest were in no case relevant enough to justify an exclusion of the individuals from certain segments or voting. 


\section{Dissemination and implementation}

The guideline will be disseminated via the "Pneumologie" medical journal and can be viewed online on the AWMF homepage (http://www.awmf.org/awmf-online-das-portal-der-wissenschaftlichen-medizin/awmf-aktuell.html).

\section{Validity and updating process}

The guideline will be valid for five years following the date of its publication.

\section{Preamble}

Scope of application of the guideline: reliable and probable diagnosis of IPF and for all patients who, following a multidisciplinary team (MDT) evaluation, receive the principal diagnosis of IPF (see below).

\section{A. Discussion and evaluation of individual pharmacological therapies}

\section{Shall IPF patients be treated with a combination therapy of corticosteroid, azathioprine and acetylcysteine?}

Acetylcysteine is a precursor to the antioxidant glutathione, the level of which may be reduced in the lungs of IPF patients [3,4]. A randomized controlled trial has been published that compares the effect of high-dose acetylcysteine (i.e. $600 \mathrm{mg}$ t.i.d.) versus placebo in patients under treatment with prednisone plus azathioprine [5]. In this trial, the decrease of the vital capacity and the diffusion capacity after 12 months in the treatment arm with acetylcysteine was significantly smaller (vital capacity: difference of $0.18 \mathrm{I}$; $95 \%$ confidence interval $[\mathrm{Cl}], 0.03-$ 0.32 ; $\mathrm{P}=0.02$; diffusion capacity: difference of $0.75 \mathrm{mmol} /$ $\mathrm{min} / \mathrm{kPa} ; 95 \% \mathrm{Cl}, 0.27-1.23 ; \mathrm{P}=0.003)$. In terms of mortality or other secondary endpoints including dyspnea, quality of life, exertion physiology or radiological appearance, no differences were observed. The limitations of this trial include a considerable dropout rate (approx. 30\%, incl. deaths), the absence of a pure placebo arm and use of the "last observation carried forward" methodology for missing values which carries the risk of overrating therapeutic effects $[6,7]$. In a more recent, threearm trial (PANTHER trial) the combination of $\mathrm{N}$-acetylcysteine plus prednisone plus azathioprine was compared to $\mathrm{N}$-acetylcysteine monotherapy or placebo [8]. The triple arm had to be discontinued prematurely due to an increased mortality and hospitalization rate. Up to this point there had been no significant difference in the primary endpoint (FVC reduction) and in

RECOMMENDATION

IPF patients shall not be treated with a combination therapy of corticosteroid, azathioprine, and acetylcysteine (A, 1-b). other endpoints between the triple therapy and placebo [8]. This leads to the conclusion that the triple therapy tends to be harmful and not effective for IPF.

\section{Shall IPF patients be treated with an acetylcysteine monotherapy?}

When the triple therapy arm of the PANTHERtrial was discontinued, only $60 \%$ of the patients had been recruited. The continuation of the trial-following a short-term interruption - with further recruitment in the remaining two arms, leading to the inclusion of 133 patients in the verum [active drug] and 131 in the placebo group, did not produce any significant difference either in the primary endpoint (change in forced vital capacity) or in most of the secondary endpoints (e.g. other pulmonary function parameters) [9]. Positive, partially significant effects were observed with regard to 6MWT and some quality of life scores. The temporary interruption with partial unblinding (knowledge of the behavior of the placebo arm up to that point in time) ihas to be considered a weakness of the trial. A subgroup analysis of the patients who were recruited before and after the interruption resulted in significant differences in the outcome. For nearly all endpoints, the subgroup before the interruption revealed a trend of positive effects of the monotherapy with acetylcysteine, which were even significant for the DLCO and the 6-min-walk distance, while this was reversed in the subgroup following the interruption [9].

Whether monotherapy with acetylcysteine might be associated with a significant response to therapy in IPF individuals with specific polymorphisms such as TOLLIP rs3750920, as a recently published PANTHER analysis suggested, will have to be assessed in further prospective, randomized studies, as the analysis was exploratory, post-hoc and based on a low case number [10]. If this observation should prove to be reproducible, it would be tantamount to the first individualized therapy approach to IPF.

RECOMMENDATION

IPF patients should not be treated with an acetylcysteine monotherapy (B, 2-b).

\section{Shall IPF patients be treated with vitamin $\mathrm{K}$ antagonists?}

Epidemiological studies from the United States and Denmark show increased thromboembolic (acute coronary syndrome, deep vein thrombosis) mortality in patients who later developed an IPF $[11,12]$. Evidence of hypercoagulability in IPF prompted trials for IPF therapy with warfarin. A small Japanese trial showed a favorable effect, in combination with prednisolone, on overall mortality and resulted in a larger trial being initiated in the United States $[13,14]$. This trial with a combined endpoint had to be stopped prematurely because the verum [active drug, warfarin] group exhibited a higher mortality and showed no advantage in the secondary endpoints [14]. A post- 
hoc analysis of the placebo arms of the approval trials for pirfenidone showed a higher mortality (hazard ratio: 4.7) in IPF patients who were anticoagulated due to cardiovascular IPF indications (e.g. atrial fibrillation) [15].

Two retrospective, monocentric analyses revealed similarly higher mortality rates in IPF patients under therapeutic anticoagulation in comparison to those without anticoagulants $[16,17]$.

\section{RECOMMENDATION}

IPF patients shall not be treated with vitamin $\mathrm{K}$ antagonists to treat the primary disease IPF (A, 1-b).

\section{Shall IPF patients be treated with the tyrosine kinase inhibitor imatinib?}

Imatinib is a tyrosinekinase inhibitor which inhibits the signal transduction of TGF-b, PDGF and other cytokines, thus reducing the release of extracellular matrix and blocking the transdifferentiation of fibroblasts into myofibroblasts. These properties gave rise to hope for an effect on IPF and prompted a double-blind placebo-controlled trial. Mortality and disease progression showed no significant differences between the two groups [18].

RECOMMENDATION

IPF patients shall not be treated with imatinib (A, 1-b).

\section{Shall IPF patients be treated with the endothelin receptor $A$ antagonist ambrisentan?}

In IPF, evidence of a higher expression of ET-A and ET-B receptors has been provided [19]. Both selective (ambrisentan) and dual antagonists (bosentan, macicentan) have been tested for treating IPF. In a double-blind, placebo-controlled trial, the effect of ambrisentan on the progress of pulmonary fibrosis in IPF patients (only $10 \%$ with secondary pulmonary hypertension) was investigated. The study had to be stopped prematurely as treatment with ambrisentan, either in the total cohort or stratified by pulmonary hypertension, resulted in an accelerated disease progression with increased respiratory hospitalizations and higher mortality, as compared to placebo [20].

RECOMMENDATION

IPF patients shall not be treated with ambrisentan (A, 1-b).
Shall IPF patients be treated with the dual endothelin receptor antagonists (ET-A and ET-B) bosentan or macitentan?

Two randomized and placebo-controlled (RC) trials on bosentan $[21,22]$ and one RC trial on macitentan have been published [23]. In BUILD-1 (Bosentan Use in Interstitial Lung Disease), 158 IPF patients were randomized to either placebo or bosentan and followed up for 12 months [24]. BUILD-1 revealed no effect of bosentan on mortality (RR, 1.14; $95 \% \mathrm{Cl}, 0.24-5.54$ ), however, a positive signal ( $R R, 0.62 ; 95 \% \mathrm{Cl}, 0.37-1.05)$ was apparent for a combined endpoint of time to death or disease progress that was based on pulmonary function and clinic. In addition, bosentan therapy showed no significant increase in the number of adverse events or serious adverse events. In the subsequent trial, BUILD-3, in a larger cohort of 616 IPF patients, only patients with histological evidence of UIP were included [22]. However, in spite of the modified design of the trial, it was not possible to demonstrate a conclusive effect for bosentan on mortality ( $R R, 1.25 ; 95 \% \mathrm{Cl}, 0.53-2.96)$ or disease progress (RR, 1.25; $95 \% \mathrm{Cl}, 0.53$ - 2.96) in BUILD-3 either. Furthermore, there were no significant differences for the endpoints FVC, quality of life (36-Item Short Form Health Survey), dyspnea, adverse events and serious adverse events [22].

Macitentan, a new dual ERA, was tested against placebo in a phase 2 trial in 178 IPF patients with histological evidence of UIP [23]. Similar as in the case of bosentan, the trial for the patients treated with macitentan revealed no significant effect on survival (RR, 0.74; $95 \% \mathrm{Cl}, 0.13-4.33)$, progression-free survival (RR 1.02; $95 \% \mathrm{Cl}, 0.63-1.66$ ) or FVC decline (mean difference, $0.00 ; 95 \% \mathrm{Cl}, 20.16$ to 0.16 ). Furthermore, there was no difference in the rate of reported adverse events or serious adverse events [23]

Due to the relatively similar mechanisms of action, the data of all three studies were analyzed together [2]. Even this pooled analysis revealed no significant therapeutic effects.

\section{RECOMMENDATION}

IPF patients shall not be treated with bosentan or macitentan to treat the primary disease IPF (A, 1-b).

\section{Shall IPF patients be treated with the PDE5 inhibitor sildenafil?}

Sildenafil is an orally available phosphodiesterase (PDE)-5 inhibitor which has been tested in two randomized controlled trials with IPF patients [24,25]. In the STEP-IPF (Sidenafil trial of exercise performance in IPF) Phase 3 trial 180 IPF patients with a TLco $<35 \%$ predicted, and thus advanced IPF, were included. After randomization the patients received either $3 \times 20$ mg sidenafil or placebo daily for a total of 12 weeks, followed by an open label phase with verum [active drug, sildeafil] for another 12 weeks. The primary endpoint consisted of the percentage of patients who showed at least a $20 \%$ increase in the 6- 
minute walk test (6MWT) by the end of the first 12 weeks. This endpoint was not achieved in the trial (Sildenafil $10.1 \%$ vs Placebo $6.6 \%, p=0.39$ ) [25]. Yet, in some secondary endpoints such as dyspnea level, quality of life, TLco and oxygen saturation, discrete and eventually statistically significant improvements were observed under application of sildenafil [25]. A post-hoc analysis in a subgroup of patients revealed that treatment with sildenafil in patients with obvious right ventricular hypertrophy or RVSP led to a significant improvement of the 6MWT distance of $99.3 \mathrm{~m}$ and QoL [26]. But it should be noted that in the STEP-IPF trial, not all patients were consistently examined for right ventricular stress. Furthermore, no stratification was made in terms of right ventricular stress either. These circumstances limit the validity of the trial.

\section{RECOMMENDATION}

IPF patients should not be treated with sildenafil to treat the primary disease IPF (B, 2-b).

\section{Shall IPF patients be treated with an antacid medication?}

Depending on the design of the study, information about the frequency of gastroesophageal reflux disease (GERD) with IPF varies between 0 and $94.1 \%$ [55]. Two retrospective analyses reported a prognostic significance of GERD in IPF patients [56, 57]. In both publications, the presence of GERD is associated with a better prognosis, reasons for this being unclear. One explanation might be that reflux-associated discomforts lead to diagnostic work-up resulting in IPF being diagnosed earlier, resulting in "lead time bias." Other reasons stated are the associations between GERD and IPF which are not clearly understood yet. Some data support the notion that (micro) aspirations of acidic (and possibly non-acidic) stomach contents may cause parenchyma damage leading to pneumonitis, contribute to increased epithelium permeability and initiate, exacerbate or maintain a fibrotic proliferation[58]. In addition, an association between microaspirations and an acute exacerbation of IPF has been postulated [59]. According to these data, the question of whether a GERD therapy with antacid medication might also have a positive effect on the course of IPF has been debated for some time [56, 60].

Several, mostly retrospective analyses or observational studies have investigated the influence of antacid medication with respect to a reduced disease progression of IPF [60-63]. In this context, a retrospective analysis of a longitudinal cohort showed a survival advantage for IPF patients who received an antacid medication for medical reasons (HR, 0.47; $95 \% \mathrm{Cl}$, 0.24 -0.93; adjusted analyses) [56]. In another study, all patients from the placebo groups of three randomized trials of the IPFnet trial were examined in a pre-specified post-hoc analysis [62]. This revealed that patients who were under antacid medication at the time of being included in the trial had a significantly smaller decline of FVC in the observation period than patients without this medication (mean difference $0.07 \mathrm{~L} ; 95 \%$ $\mathrm{Cl}, 0-0.14 ; \mathrm{P}=0.05)$. In addition, no adjudicated acute exacerbations were found in patients under antacid medication. However, neither a survival difference nor a lower hospitalization rate was observed. By contrast, in a recent post-hoc analysis of the placebo arms of the CAPACITY and the ASCEND trials antacid therapy was not found to beneficially affect disease progression, overall and IPF-associated mortality, or decrease and course of FVC [63]. On the contrary, the rate of hospitalizations showed a non-significant shift to the disadvantage of patients under antacids $(p=0.0522)$. Two other post-hoc analyses trials, one of which, however, has not been published in full yet [65], also investigated the influence of antacid medication on the course of the disease under an anti-fibrotic therapy and found no positive effects $[64,65]$.

From the guideline committee's point of view the available data is inadequate to enable an appraisal of an effect of an antacid medication on the pathological progression of IPF.

\section{RECOMMENDATION}

Treatment of IPF patients with antacids for their primary disease cannot be recommended (C, 4).

\section{COMMENT}

If reflux is present, it is recommended to treat gastroesophageal reflux disease in accordance with the existing guidelines as one would do in non-IPF patients.

\section{Shall IPF patients be treated with nintedanib?}

Nintedanib is an intracellular inhibitor of several receptor tyrosine kinases and in particular inhibits the signaling through Vascular Endothelial Growth Factor (VEGF), Fibroblast Growth Factor (FGF) and Platelet Derived Growth Factor (PDGF) pathways.

Nintedanib has been investigated on IPF patients in three randomized controlled trials: one phase II trial (TOMORROW) and two twin-phase III trials (INPULSIS-1 and-2) [27,28]. - Table 4 provides a comparative overview of the main inclusion criteria of the most important trials on nintedanib and pirfenidone.

In a phase II trial, the safety and efficacy of four different nintedanib doses $(50$ mgb.i.d., $100 \mathrm{mg}$ b.i.d., $150 \mathrm{mg}$ b.i.d. and $150 \mathrm{mg}$ b.i.d.) versus placebo were investigated [27]. The primary endpoint, FVC decline after one year, showed a clear signal in favor of the therapy with nintedanib in the dose of 150 mgb. i. d., but in the pre-specified analysis statistical significance was missed $(p=0.06)$. In addition, under this dose significantly fewer acute exacerbations occurred in the nintedanib arm compared with the placebo control (HR, 0.16; $95 \% \mathrm{Cl}$, $0.03-0.70$ ), and quality of life, measured by means of SGRQ, showed a significant difference in favor of nintedanib. There were no significant differences in terms of mortality [27]. 
- Table 4 Inclusion criteria of current clinical trials of IPF therapy [27-30,48].

\begin{tabular}{|c|c|c|c|c|}
\hline & TOMORROW & INPULSIS 1 and 2 & CAPACITY 1 and 2 & ASCEND \\
\hline Age (years) & $40-80$ & $\geq 40$ & $40-80$ & $40-80$ \\
\hline FVC (\% target) & $\geq 50$ & $\geq 50$ & $50-90^{1}$ & $50-90$ \\
\hline DLco (\% target) & $30-79$ & $30-79$ & $35-90^{1}$ & $30-90$ \\
\hline FEV1/FVC (\%) & $\mathrm{N} / \mathrm{A}$ & $\mathrm{N} / \mathrm{A}$ & $\mathrm{N} / \mathrm{A}$ & $\geq 80$ \\
\hline 6MWD (m) & $\mathrm{N} / \mathrm{A}$ & $\mathrm{N} / \mathrm{A}$ & $\geq 150$ & $\geq 150$ \\
\hline \multicolumn{5}{|l|}{ Diagnosis } \\
\hline Initial diagnosis & max. 5 years & max. 5 years & max. 2 years & max. 4 years \\
\hline Definite IPF & yes & yes & yes & yes \\
\hline Possible IPF with $\mathrm{TB}^{2}$ on HRCT & yes & yes & no & no \\
\hline \multicolumn{5}{|l|}{ Concomitant therapy } \\
\hline Prednison/olone & $\leq 15 \mathrm{mg} / \mathrm{d}$ & $\leq 15 \mathrm{mg} / \mathrm{d}$ & no $^{3}$ & no $^{3}$ \\
\hline \multicolumn{5}{|c|}{$\begin{array}{l}\text { FVC = forced vital capacity; DLco = diffusion capacity } ; \mathrm{FEV} 1 / \mathrm{FVC}=\text { quotient from one-second capacity and forced vital capacity (Tiffeneau Index); } 6 \mathrm{MWD}=\text { six minut } \\
\text { walking distance; IPF= idiopathic pulmonary fibrosis; } \mathrm{HRCT}=\text { high-resolution computed tomography. } \\
{ }^{1} \mathrm{FVC} \text { and } / \text { or DLCO } \geq 90 \% \text { of predicted values were not allowed. } \\
{ }^{2} \mathrm{~TB}=\text { traction bronchiectasis; without histological proof of UIP pattern. } \\
{ }^{3} \text { Corticosteroids for the treatment of IPF were not allowed, but were allowed for the treatment of other disease and transiently for the treatment of acute exacer- } \\
\text { bations of IPF. }\end{array}$} \\
\hline
\end{tabular}

The INPULSIS-1 and INPULSIS-2 (Safety and Efficacy of nintedanib in Idiopathic Pulmonary Fibrosis) trials were identically designed phase III trials in which a total of 1,066 patients were randomized at a $3(150 \mathrm{mg}$ nintedanib b.i.d.) versus 2 (placebo) ratio and observed over a period of 52 weeks [28]. Both trials showed a consistent, significant reduction of the primary endpoint, i. e. of the annual FVC decline by approx. $50 \%$ (INPULSIS-1 from $239.9 \mathrm{~mL} /$ year to $114.7 \mathrm{~mL} /$ year; INPULSIS-2 from $207.3 \mathrm{~mL} /$ year to $113.6 \mathrm{~mL} /$ year; both $\mathrm{p}<0.001$ ). The rate of patients who had no absolute FVC decline greater than $5 \%$ or greater than $10 \%$ after 52 weeks was significantly higher in both trials under nintedanib than under placebo treatment [28]. One key secondary endpoint was the time to first acute exacerbation, as reported by the investigator or after adjudication of the events by a blinded adjudication committee. For this endpoint, there was no effect in INPULSIS 1 (HR 1.15; $95 \% \mathrm{Cl}$, $0.54-2.42 ; p=0.67$ ) whereas a beneficial effect was found in INPULSIS 2 (HR 0.38, $95 \% \mathrm{Cl} 0.17-0.77$; $<$ 0.005). Quality of life, measured by means of the St. George Respiratory Questionnaire (SGRQ), was another key secondary endpoint. There was no difference shown in INPULSIS 1 (SGRQ total score -4.34 points under nintedanib versus -4.39 points under placebo; $\mathrm{p}=0.97$ ) but a significantly smaller drop in points (= worsening) under nintedanib in INPULSIS $2(-2.80$ points versus -5.48 points; $\mathrm{p}=0.02$ ).

In the pre-specified pooled analysis of INPULSIS 1 and 2 studies, the effect for the investigator-reported acute exacerbations was not significant (HR 0.64; $95 \% \mathrm{Cl}, 0.39-1.05 ; \mathrm{p}=$ 0.08 ), however, for the adjudicated acute exacerbation events, there was a significant positive effect ( $\mathrm{HR} 0.32$; $95 \% \mathrm{Cl}, 0.16$ $0.65 ; p=0.01)[28,29]$. The pre-specified, pooled analysis of the total SGRQ score showed no significant effect ( -3.53 points versus 4.96 points; $p=0.09$ ) [28,29]. A recently published pooled analysis of all three trials resulted in a statistically significant extension of the time to first investigator-reported acute exacerbation, but otherwise revealed no major change compared to the previously described results [30].

The pooled analysis of INPULSIS 1 and 2 resulted in a numerical reduction, but in no significant effect with regard to overall mortality (HR 0.70; $95 \% \mathrm{Cl}, 0.43-1.12 ; \mathrm{p}=0.14)$ [28].

As major side effects, the pooled analysis revealed diarrhea and nausea (see $>$ Table 5).

In total, even under nintedanib $150 \mathrm{mg}$ b.i.d., similarly frequent reactions of adverse events ( $\mathrm{AE}, 95.3 \%$ ) or serious adverse events (SAE, 26.7\%) occurred as in the placebo arm (AE 89.8\%; SAE 23.4\%), however, diarrhea and other gastrointestinal side effects in particular were more frequent.

Table 5 Side effects - pooled analysis of INPULSIS 1 and 2 (modif. acc. to [30]).

\begin{tabular}{|l|l|c|}
\hline Side effects & $\begin{array}{l}\text { Nintedanib } \\
(\mathbf{2} \times \mathbf{1 5 0} \mathbf{~ m g / d )}\end{array}$ & Placebo \\
\hline Any side effect (all, TEAE) [\%] & 95.3 & 89.8 \\
\hline $\begin{array}{l}\text { Serious side effects } \\
\text { (all, TEAE) [\%] }\end{array}$ & 26.7 & 23.4 \\
\hline Diarrhea [\%] & 61.5 & 17.9 \\
\hline Nausea [\%] & 24.3 & 7.1 \\
\hline Vomiting [\%] & 11.8 & 3.0 \\
\hline TEAE=treatment emergent adverse event & \\
\hline
\end{tabular}


Furthermore, several post-hoc analyses concerning subgroups of the INPULSIS trials have most recently been published: with reference to gender, age, race, baseline FVC, baseline SGRQ, smoker status, use of systemic steroids and of bronchodilators, as well as HRCT pattern, no differences in terms of effect size were revealed even with diverse threshold values or in Asian patients [31-34]. Patients with advanced IPF (FVC below $50 \%$ predicted) studied within the INPULSIS extension trial INPULSIS-ON showed a similar treatemnt effect of nintedanib on decline of FVC in comparison with patients with less advanced IPF and "preserved" lung function [35]. Initial reports from the real-world use of nintedanib have since emerged for Germany, reporting a comparable amelioration of disease progression as in the trials and no occurrence of new adverse events [36]. The authors consider the pooled data more convincing than the meta and network analyses published to date, which have revealed no discrepant information either [37 - 39].

From the guideline committee's point of view, the trials demonstrate that nintedanib has a positive and clinically relevant effect on disease progression in IPF, with an overall acceptable tolerability.

RECOMMENDATION

IPF patients shall be treated with nintedanib (A, 1-a)

\section{Shall IPF patients be treated with pirfenidone?}

Pirfenidone is an oral antifibrotic drug with pleiotropic effects. It has been demonstrated that it regulates important profibrotic and proinflammatory cytokine cascades in vivo [40] and weakens fibroblast proliferation and collagen synthesis in animal models of pulmonary fibrosis [41-43].

Pirfenidone has been investigated in patients with IPF in an open-phase II trial [44], a randomized phase II trial [45] and four phase III trials [46-48]. > Table 4 provides a comparative overview of the main inclusion criteria for the most important trials of nintedanib and pirfenidone.

A randomized Japanese phase II trial $[1,800 \mathrm{mg} / \mathrm{d}]$ was discontinued prematurely after a secondary endpoint - acute exacerbation - had occurred significantly more often in the placebo group than in the pirfenidone arm [45]. Following the premature discontinuation, there was no significant effect on the primary endpoint of oxygen saturation under exercise (mean treatment duration of nine months) whereas a significantly smaller decrease in vital capacity in the verum [active drug, pirfenidone] treatment arm compared with placebo was reported $(p=0.036)[45]$.

In a phase III, randomized, controlled Japanese trial, a significantly smaller decline in vital capacity over a period of 52 weeks was found in the pirfenidone arms $(1200 \mathrm{mg}$ or 1800 daily or placebo) $(-90 \mathrm{ml}$ under $1800 \mathrm{mg} / \mathrm{d}$ compared with $-160 \mathrm{ml}$ under Placebo, $\mathrm{p}=0.04$ ) [46]. In addition, as a secondary endpoint, a difference in progression-free survival (defined as death or $>10 \%$ decrease in vital capacity) was revealed in fa- vor of the pirfenidone therapy $(p=0.03)$, whereas there was no difference in the frequency of exacerbations. This trial, however, had significant limitations; in particular, the primary endpoint of the trial was modified before the trial was unblinded.

The phase III trials CAPACITY 1 and 2 [47] were two identically designed trials with different dosing arms: CAPACITY- 1 included 435 patients and randomized between 3 groups: highdose pirfenidone $[2,403 \mathrm{mg} / \mathrm{d}]$, low-dose pirfenidone [1,197 $\mathrm{mg} / \mathrm{d}$ ] and placebo, whereas CAPACITY-2 included 344 patients and randomized between 2 groups: high-dose pirfenidone [2,403 mg/d] and placebo. In CAPACITY 1 , pirfenidone showed a significant reduction of FVC decline after 72 weeks of therapy (mean change from baseline abs. $-8.0 \%$ vs. $-12.4 \%$ target, $p=$ $0.01)$. The results of the lower pirfenidone dose were intermediate to the high dose. However, CAPACITY 2 showed no significant advantage over 72 weeks compared with placebo $(-9.0 \%$ vs. $-9.6 \%, p=0.50)$. Some secondary efficacy variables (categorical change of FVC, progression-free survival and 6MWT) were significantly better in one of the two trials, respectively. In a pooled analysis of both trials (high dose vs. placebo) under pirfenidone, the primary endpoint of FVC decline $(p=$ 0.005 ), the categorical decline in FVC $>10 \%$ (absolute difference $9.1 \%, p=0.003$ ), the progression-free survival (HR 0.74 , $\mathrm{p}=0.025$ ) and the 6-MWT walk distance (absolute difference $24 \mathrm{~m}, \mathrm{p}=0.0009$ ) proved to be significantly better. During the 72 week treatment period overall mortality was numerically but not statistically significant in favor of pirfenidone (pooled

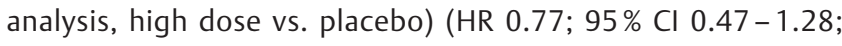
$\mathrm{p}=0.315)$ [47].

In the ASCEND trial (A Randomized, Double-Blind, Placebo Controlled Trial of Pirfenidone in Patients with Idiopathic Pulmonary Fibrosis), 555 IPF patients were randomized into either a pirfenidone $(2,403 \mathrm{mg} / \mathrm{d})$ or a placebo arm [48]. In comparison with the CAPACITY trials, the ASCEND trial had stricter inclusion criteria [see $>$ Table 4 ; $>95 \%$ definitive IPF]. Consequently, 1,007 out of 1,562 screened patients were excluded. The trial showed a significant effect on the primary endpoint, the decline in FCV (absolute \% predicted) after 52 weeks which, under pirfenidone, was found to be $45.1 \%$ lower as compared to placebo. Pirfenidone reduced the proportion of patients with a decline in FVC $>10 \%$ predicted or dead after 52 weeks significantly by $47.9 \%(p<0.001)$. When, in analogy to the INPULSIS trials, the annual FVC decline was calculated using the slope analysis, a significant, $41.5 \%$ reduction of the FVC decline from $280 \mathrm{~mL} /$ year (placebo) to $164 \mathrm{ml} /$ year (pirfenidone) was evident. With respect to the two main secondary endpoints, pirfenidone significantly reduced the decrease in walking distance in the 6 -minute walk test $(p=0.04)$ and improved progression-free survival compared with placebo (HR $0.57 ; 95 \% \mathrm{Cl}$ $0.43-0.77 ; p<0.001)$. In terms of mortality, a numerical reduction was observed, which was not statistically significant (HR 0.55; $\mathrm{Cl} 0.26-1.15 ; \mathrm{p}=0.10)$ [48].

A pre-specified pooled analysis $(n=1247)$ of the two CAPACITY trials and the ASCEND trial included all patients with a dose of $2403 \mathrm{mg}$ pirfenidone as well as all placebo patients and analyzed the effect over the period of 52 weeks [49]. Pirfenidone reduced the proportion of patients with a decline in 
- Table 6 Relevant side effects under pirfenidone - pooled analyses acc. to [50]

\begin{tabular}{|l|l|l|}
\hline Side effects & Pirfenidone & Placebo \\
\hline Any side effect (all, TEAE) [\%] & 99.0 & 97.9 \\
\hline Serious side effects (all, TEAE) [\%] & 27.0 & 28.5 \\
\hline Nausea [\%] & 36.1 & 15.5 \\
\hline Skin rash [\%] & 30.3 & 10.3 \\
\hline Anorexia [\%] & 13.0 & 5.0 \\
\hline TEAE = treatment emergent adverse event & \\
\hline
\end{tabular}

FVC $\geq 10 \%$ or death compared with placebo by $43.8 \%(95 \% \mathrm{Cl}$ $29.3-55.4 \%, p<0.001)$. In addition, pirfenidone reduced the decline in FVC by $40.7 \%$ compared with placebo $(p<0.001)$. Also, a significant therapy benefit with respect to progressionfree survival, the walking distance in the 6-MWT and the dyspnea score was described. Pooled analyses of overall mortality included in the publication of the ASCEND trial showed a significant benefit under pirfenidone treatment (HR 0.52; $\mathrm{Cl} 0.31$ $0.87, \mathrm{p}=0.01)[48,49]$.

A pooled analysis over 1 year of pirfenidone therapy revealed similar frequencies of adverse events (AE, 99\%) or serious adverse events (SAE, 27.0\%) as in the placebo arm (AE $98 \%$; SAE $28.5 \%$ ). However, skin rash, nausea and anorexia in particular were more frequent with pirfenidone ( $\triangleright$ Table 6 ) $[49,50]$.

Furthermore, several post-hoc analyses concerning subgroups of the CAPACITY and ASCEND trials have recently been published: with regard to region, gender, age, race, baseline FVC, baseline 6-MWT, baseline DLCO, baseline FEV1/FVC ratio, time since diagnosis and baseline GAP index, smoker status, LTOT, even in the case of different threshold values, no differences in effect size of treatment with pirfenidone was reported $[50,51]$.
In addition, real-world data on the use of pirfenidone in Germany have been published as well, reporting therapeutic effects similar to those of the trials with no new occurrences of adverse events [52-54]. The authors consider the pooled data more convincing than the meta and network analyses published to date [37-39], which did not reveal any discrepant information either.

From the guideline committee's point of view, the trials demonstrate that pirfenidone has a positive and clinically relevant effect on disease progression in IPF, with an overall acceptable tolerability.

\section{RECOMMENDATION}

IPF patients shall be treated with pirfenidone (A, 1-a).

- Table 7 provides an overview of the recommendations for IPF therapy.

\section{B. Discussion and general recommenda- tions for antifibrotic therapy of IPF}

The following recommendations are exclusively based on expert opinion and, therefore, all of them should be allocated to evidence level 5.

\section{When should antifibrotic therapy be started?}

Although only patients with mild or moderate IPF were included in the clinical trials with pirfenidone and nintedanib, the FDA has approved both drugs without limitation for all patients with IPF. The European Medicines Agency (EMA) has approved pirfenidone only for patients with mild and moderate IPF. No limitations were issued for nintedanib. It must be noted that both drugs are approved exclusively for IPF, not for any other ILD di-

\begin{tabular}{|c|c|c|}
\hline The following medications are not recommended for treating IPF & Recommendation level & Evidence level \\
\hline “Triple Therapy” (Prednisolone, azathioprine, acetylcysteine) & A & $1-b$ \\
\hline Acteylcysteine monotherapy ${ }^{1}$ & B & $2-b$ \\
\hline Anti-coagulation with vitamin-K antagonists & A & $1-b$ \\
\hline Imatinib & A & $1-b$ \\
\hline Ambrisentan & A & $1-b$ \\
\hline Dual endothelin receptor antagonists ${ }^{1}$ (i. e. bosentan, macitetan) & A & $1-b$ \\
\hline Phosphodiesterase- 5 inhibitor sildenafil ${ }^{1}$ & B & $2-b$ \\
\hline Antacid therapy as an IPF therapy with no indication of reflux & $\mathrm{C}$ & 4 \\
\hline The following medications are recommended for the treatment of IPF & Recommendation level & Evidence level \\
\hline Nintedanib & A & 1-a \\
\hline Pirfenidone & A & 1-a \\
\hline
\end{tabular}




\section{RECOMMENDATION}

All patients with a definite, ideally multidisciplinary diagnosis of IPF shall be informed in detail about the disease, its natural history including acute exacerbations, as well as treatment options and their effects and adverse effects.

agnosis. Therefore, a correct IPF diagnosis is of crucial importance.

An early initiation of therapy at the time of diagnosis appears to be reasonable in order to slow down disease progression measured in terms of pulmonary function with the aim of improving the prognosis. The available literature demonstrates that antifibrotic therapy with pirfenidone or nintedanib is equally effective in terms of slowing down disease progression across all the functional degrees of severity investigated. It is important that in the placebo arms, patients with "normal" FVC (>90\% in the nintedanib trials; $>80 \%$ in thepirfenidone trials) exhibited a comparably significant absolute FVC loss as compared to patients with significant restriction. Hence, a spirometry indicating values in the normal range of predicted appears to be no reason not to offer antifibrotic therapy to an IPF patient $[31,51,54,71,72]$. In addition, it must be noted that in the case of patients with emphysema and IPF (so-called Combined Pulmonary Fibrosis and Emphysema, CPFE) FVC is not suitable for judging the severity and progression of the disease.

\section{RECOMMENDATION}

Symptomatic patients diagnosed with definite IPF - ideally in multidisciplinary team discussion - shall be recommended to start antifibrotic therapy at the time of diag$\operatorname{nosis}(\mathrm{A})$.

\section{EXPLANATION}

In special cases (e.g. incidental finding during CT examination or lung resection for other indication) of nonsymptomatic patients with no or only minimal limitation of the pulmonary function a wait-and-watch approach concerning the initiation of therapy can initially be adopted. Also, prognosis-limiting concomitant diseases (e. g. lung cancer) may be a reason not to initiate an antifibrotic therapy. In any event, the individual therapeutic approach has to be discussed with the patient in an open and understandable manner. Even if a decision is made against an immediate initiation of therapy, the patient should always be subjected to continuous clinical monitoring and control of pulmonary function (at least every 3 months).

\section{When should antifibrotic therapy be discontinued?}

In principle, therapy failure or non-tolerable side effects may justify a discontinuation of therapy. There is no standard definition for therapy failure. The available data with regard to treatment periods exceeding $52-71$ weeks, i.e. with longer therapy periods than in the approval trials, is limited $[28,47,48]$. Currently, the results of two long-term observation trials of pirfenidone are expected - RECAP and PASSPORT (Pirfenidone PostAuthorization Safety Registry) [66,67]. Integrated long-term analyses of 1299 patients from 5 clinical trials demonstrate that pirfenidone is tolerated well even over a long-term period of up to 9.9 years (median 1.7 years) [50]. In addition, several publications of so-called real-world data from individual pulmonary fibrosis centers are available now. These data confirm the favorable effect of antifibrotic therapy on pulmonary function with clinically acceptable tolerability [36, 52, 53, 68 - 70]. A long-term observational trial with nintedanib is still ongoing (INPULSIS ON). A study on clinical real-world experiences with nintedanib in Germany has recently been published. This study confirmed the reduction in the decline of pulmonary function with acceptable tolerability over therapy duration of 9 months, even following a change from another antifibrotic therapy [36].

\section{RECOMMENDATION}

In the light of the high mortality of IPF, an antifibrotic therapy which is well tolerated by the patient shall be continued without limitation or until lung transplantation, possibly including a switching between the two approved antifibrotic drugs (A).

The antifibrotic treatment shall be discontinued when side effects, in spite of symptomatic therapy, dose reductions or temporary interruptions of treatment, cannot be controlled (A).

Shared decision-making with the patient shall be the basis for discontinuation of therapy $(A)$.

\section{When should a switch of antifibrotic drugs be recommended?}

There is no clear definition for the presence of a disease progression under therapy, and thus the evaluation of the treatment effect is primarily based on the experience of the treating physician. That is a fundamental problem. In addition to pulmonary function parameters (FVC, CO diffusion), clinical factors (dyspnea, cough, exercise capacity, etc.) and possible complications (e.g. exacerbations, hospitalizations, pulmonary hypertension) must be taken into account in order to obtain a comprehensive understanding of the course of the disease.

In larger cohorts, it has been well documented that a decline in FVC $>10 \%$ predicted within 6 months is associated with a higher mortality risk $[73,74]$. However, it remains an unresolved question, wether such a rapid FVC loss has to be rated as treatment failure in every individual case [74]. In a post-hoc analysis of the CAPACITY and ASCEND trials, it was shown that patients who exhibited a decline in FVC $>10 \%$ within the first 6 
months still had a better course of their disease and prognosis under continued treatment with pirfenidone during the following 6 months as compared to the placebo group [75]. Similar data, published only in abstract form to date, are available for nintedanib as well [76].

A therapy change to nintedanib following the discontinuation of pirfenidone due to intolerance or disease progression is possible [77]. Based on clinical experience, this also applies to a change from nintedanib to pirfenidone; however, relevant published data are not available yet.

\section{RECOMMENDATION}

Any change of therapy should be decided only after a thorough and comprehensive evaluation of progression rate, symptom load and side effects and together with the patient; change of therapy should include the option of participating in a clinical treatment trial (B).

\section{Is antifibrotic combination therapy an option?}

Due to the availability of two approved antifibrotic drugs, the question arises if, similar to other diseases (e. g. bronchial asthma, COPD, PAH or lung carcinoma), a combination therapy might represent an even more effective therapeutic approach. The multifactorial and heterogeneous pathogenesis of IPF and the related necessity to systematically influence diverse profibrotic signal pathways by pharmacological treatments is a clear rationale for a combination therapy [78]. However, it is unclear if the combination of two effective active drugs will lead to a synergistic or additive effect or if the two drugs might even antagonize, i.e. weaken, the effects of each other. A precedence case is the PANORAMA trial in which the combination of pirfenidone and acetylcysteine vs. pirfenidone and placebo was investigated, in which not only no positive effect but possibly even a negative effect of adding acetylcysteine to pirfenidone was encountered [79]. Likewise, one can never exclude unforeseeable interactions of medication with unacceptable side effects. In a Japanese phase-2 trial, the profile of side effects, tolerability and pharmacokinetics of nintedanib alone and in combination with pirfenidone were investigated for IPF patients. The investigation revealed a reduction of the maximum plasma levels and the AUC of nintedanib as well as more frequently occurring side effects in the case of co-medication with pirfenidone compared with nintedanib monotherapy [80].

Therefore, prior to an implementation of a combination therapy with pirfenidone and nintedanib controlled trials will have to demonstrate that the combination therapy exhibits a better efficacy profile and presents no safety concerns compared to the respective monotherapies.

RECOMMENDATION

Outside of controlled clinical trials, IPF patients shall not be treated with a combination of pirfenidone and ninte$\operatorname{danib}(A)$.

\section{What are the implications of the differences in the EMA approvals of pirfenidone and nintedanib?}

Keeping in mind the absence of a head-to-head comparison between nintedanib and prifenidone, the currently available literature seems not to imply a relevant superiority of either of the two active drugs over the other, so that no recommendation can be made regarding a preferential use. A comparison of the two substances is complicated by the diverse patient cohorts in the respective pivotal trials resulting from the diverse inclusion and exclusion criteria in the CAPACITY, ASCEND and INPULSIS trials [28, 47,48]. In addition, the updated international guideline in its therapy recommendations, aside from the comparable inhibition of disease progression, has not formulated any additional evidence of efficacy, such as survival advantage or reduction of acute exacerbation, for either of the two substances [2].

In Germany, nintedanib has been approved for all IPF patients without consideration of the level of severity, whereas pirfenidone has been approved only for the mild and moderate IPF. As no objective definition exist for the level of severity, the judgment of severity is up to the treating physician -ideally the multidisciplinary team - in consideration of the clinical symptoms, functional limitations, radiomorphological picture and comorbidities [71].

\section{RECOMMENDATION}

For IPF patients, the selection of the antifibrotic drug shall be made in consideration of the level of severity, the side effects profile, the comorbidities and comedications as well as the lifestyle and personal preference of the patient $(A)$.

\section{Which therapy in the case of "probable" or "possible" IPF?}

As the antifibrotic drugs have only been approved for patients with IPF and following the negative results of the PANTHER trial, treatment of these patients with a triple therapy of prednisolone, azathioprine and acetylcysteine is no longer recommended, the correct diagnosis of IPF and thus the differential diagnosis distinguishing IPF from other forms of interstitial lung disease plays a crucial role with respect to the choice of the pharmacological therapy [8] as well.The correct diagnosis of IPF should be made according to evidence-based recommendations [81]. However, a diagnosis of definite IPF according to the guidelines can be made only in about half of all patients while the remainder is diagnosed as probable or possible IPF [82]. A surgical lung biopsy, which would formally be required to settle the IPF diagnosis in patients with possible or inconsistent UIP pattern on HRCT is performed in only about $15 \%$ of respective patients, either because of unreasonably high risks such as severe functional limitations or comorbitities or because the patient refuses to undergo an invasive procedure 
with a mortality between 2-6\% [82-84]. The bronchoscopic cryobiopsy is a new diagnostic method being used at some specialized centers as a complement to or instead of a surgical lung biopsy. However, further data are required to clarify the final significance of this method in the diagnostic work-up of IPF patients [85-89]. In the event of a radiologically possible UIP pattern and lacking the option of a surgical lung biopsy, an interdisciplinary discussion of the case is of particular importance.

\section{RECOMMENDATION}

Every patient with probable or possible IPF shall be presented to a center with special expertise in the management of patients with interstitial lung diseases (A).

Subsequently, depending on the anamnestic, clinical, radiological, BAL and bioptic findings evaluated by a multidisciplinary team, a determination shall be made about the existence of an alternative diagnosis such as chronic hypersensitivity pneumonitis, idiopathic NSIP or connective tissue disease associated ILD. This will then imply the decision of whether or not to use an immunosuppressive treatment approach, for instance in highly probable chronic hypersensitivity pneumonitis or NSIP, or to commence antifibrotic therapy in highly probable IPF.

\section{RECOMMENDATION}

Every patient with probable or possible IPF shall be closely monitored (A).

If in the course of the disease an IPF-like disease progression is observed, the IPF diagnosis shall be discussed within an MDD and antifibrotic therapy initiated p.r.n. (A).

\section{EXPLANATION}

In a patient with pulmonary fibrosis which is initially not classifiable or classified as non-IPF, the further disease progression may be characteristic of IPF, with an IPF-like treatment response. In such a case, the findings and the clinical course shall be discussed in the multidisciplinary team (ILD board), the diagnosis eventually be revised to IPF, and antifibrotic therapy initiated p.r.n. (A)

The authors have stated the following conflicts of interest:

Jürgen Behr has received fees for lecturing and consulting activities from Actelion, Bayer, Boehringer-Ingelheim, Gilead, InterMune/ Roche, Novartis. Research assistance was provided by Actelion and Boehringer-Ingelheim.

Andreas Günther has received fees for lecturing and/or consulting activities from Roche, Boehringer Ingelheim Teva and Novartis as well as third-party funding within the scope of cooperation projects with Roche, Inventiva and Sanofi Aventis.
Francesco Bonella has received fees for lecturing and consulting activities from InterMune/Roche and Boehringer Ingelheim as well as third-party funding for research projects from InterMune/Roche, Boehringer Ingelheim and Serendex/Savara.

Klaus Geißler has stated no conflicts of interest.

Dirk Koschel has received fees for lecturing and consulting activities from InterMune/Roche and Boehringer Ingelheim.

Michael Kreuter has received fees for lecturing and consulting activities from InterMune/Roche and Boehringer Ingelheim as well as third-party funding for research projects from InterMune/Roche and Boehringer Ingelheim.

Antje Prasse has received fees for lecturing and consulting activities from InterMune/Roche, Boehringer Ingelheim, Bayer and Actelion as well as third-party funding for research projects from Roche and Boehringer Ingelheim.

Nicolas Schönfeld has stated no conflicts of interest.

Helmut Sitter gibt has stated no conflicts of interest.

Joachim Müller-Quernheim: Fees for lectures and/or consultancy from Roche and Norvatis. Income of the clinic within the scope of trials from Boehringer Ingelheim, Actelion, Roche and Bristol-Myers Squibb.

Ulrich Costabel has received fees for lecturing and consulting activities from InterMune/Roche and Boehringer Ingelheim, for lecturing activities from AstraZeneca, for consulting activities from Bayer, GSK, UCB Celltech, Biogen, Fibrogen as well as third-party funding for research projects from InterMune/Roche and Boehringer Ingelheim.

References

[1] Behr J, Günther A, Ammenwerth W et al. S2K-Leitlinie zur Diagnostik und Therapie der idiopathischen Lungenfibrose. Pneumologie 2013; 67: $81-111$

[2] Raghu G, Rochwerg B, Zhang Y et al. An Official ATS/ERS/JRS/ALAT Clinical Practice Guideline: Treatment of Idiopathic Pulmonary Fibrosis. An Update of the 2011 Clinical Practice Guideline. Am J Respir Crit Care Med 2015; 192: e3 - e19

[3] Cantin AM, Hubbard RC, Crystal RG. Glutathione deficiency in the epithelial lining fluid of the lower respiratory tract in idiopathic pulmonary fibrosis. Am Rev Respir Dis 1989; 139: 370 - 372

[4] Behr J, Maier K, Degenkolb B et al. Antioxidative and clinical effects of high-dose $\mathrm{N}$-acetylcysteine in fibrosing alveolitis: adjunctive therapy to maintenance immunosuppression. Am J Respir Crit Care Med 1997; 156: $1897-1901$

[5] Demedts M, Behr J, Buhl R et al. IFIGENIA Study Group. High-dose acetylcysteine in idiopathic pulmonary fibrosis. N Engl JMed 2005; 353: $2229-2242$

[6] Hunninghake GW. Antioxidant therapy for idiopathic pulmonary fibrosis. N Engl ] Med 2005; 353: 2285 - 2287

[7] Wells AU. Antioxidant therapy in idiopathic pulmonary fibrosis: hope is kindled. Eur Respir J 2006; 27: 664-666

[8] The Idiopathic Pulmonary Fibrosis Clinical Research Network. Prednisone, Azathioprine, and N-Acetylcysteine for pulmonary fibrosis. N Engl ] Med 2012; 366: 1968 - 1977

[9] Idiopathic Pulmonary Fibrosis Clinical Research. Randomized trial of acetylcysteine in idiopathic pulmonary fibrosis. N Engl J Med 2014; 370: $2093-2101$

[10] Oldham JM, Ma SF, Martinez FJ et al. TOLLIP, MUC5B, and the Response to N-Acetylcysteine among Individuals with Idiopathic Pulmonary Fibrosis. American journal of respiratory and critical care medicine 2015; 192: $1475-82$

[11] Hubbard RB, Smith C, Le Jeunel et al. The association between idiopathic pulmonary fibrosis and vascular disease: a population-based study. Am J Respir Crit Care Med 15.12 2008; 178: 1257-1261 
[12] Sode BF, Dahl M, Nielsen SF et al. Venous thromboembolism and risk of idiopathic interstitial pneumonia: a nationwide study. Am J Respir Crit Care Med 15.05 2010; 181: 1085-1092

[13] Kubo H, Nakayama K, Yanai M et al. Anticoagulant therapy for idiopathic pulmonary fibrosis. Chest 09 2005; 128: 1475-1482

[14] Noth I, Anstrom KJ, Calvert SB et al. A Placebo-Controlled Randomized Trial of Warfarin in Idiopathic Pulmonary Fibrosis. Am J Respir Crit Care Med 01.07 2012; 186: 88 - 95

[15] Kreuter M, Wijsenbeek MS, Vasakova M et al. Unfavourable effects of medically indicated oral anticoagulants on survival in idiopathic pulmonary fibrosis. Eur Respir J 06 2016; 47: 1776 - 1784

[16] Hyldgaard C, Hilberg O, Muller A et al. A cohort study of interstitial lung diseases in central Denmark. Respir Med 2014; 108: 793 - 799

[17] Tomassetti S, Ruy JH, Gurioli EtAl C. The effect of anticoagulant therapy for idiopathic pulmonary fibrosis in real life practice. Sarcoidosis Vasc Diffuse Lung Dis 2013; 30: 121 - 127

[18] Daniels CE, Lasky JA, Limper AH et al. Imatinib treatment for idiopathic pulmonary fibrosis: Randomized placebo-controlled trial results. Am J Respir Crit Care Med 15.03 2010; 181: 604-610

[19] Park SH, Saleh D, Giaid A et al. Increased endothelin-1 in bleomycininduced pulmonary fibrosis and the effect of an endothelin receptor antagonist. Am J Respir Crit Care Med 1997; 156: 600-608

[20] Raghu G, Behr J, Brown KK et al. Treatment of idiopathic pulmonary fibrosis with ambrisentan: a parallel, randomized trial. Annals of internal medicine 07.05 2013; 158: 641 -649

[21] King TE Jr, Behr J, Brown KK et al. BUILD-1: a randomized placebocontrolled trial of bosentan in idiopathic pulmonary fibrosis. Am J Respir Crit Care Med 2008; 177: 75 - 81

[22] King TE Jr, Brown KK, Raghu G et al. BUILD-3: a randomized, controlled trial of bosentan in idiopathic pulmonary fibrosis. Am J Respir Crit Care Med 2011; 184: 92 - 99

[23] Raghu G, Million-Rousseau R, Morganti A et al. Macitentan for the treatment of idiopathic pulmonary fibrosis: the randomised controlled MUSIC trial. Eur Respir ] 2013; 42: 1622 - 1632

[24] Jackson RM, Glassberg MK, Ramos CF et al. Sildenafil therapy and exercise tolerance in idiopathic pulmonary fibrosis. Lung 2010; 188 : $115-123$

[25] Zisman DA, Schwarz M, Anstrom KJ et al. A controlled trial of sildenafil in advanced idiopathic pulmonary fibrosis. N Engl J Med 2010; 363: $620-628$

[26] Han MK, Bach DS, Hagan PG et al. Sildenafil preserves exercise capacity in patients with idiopathic pulmonary fibrosis and rightsided ventricular dysfunction. Chest 2013; 143: 1699-1708

[27] Richeldi L et al. Efficacy of a tyrosine kinase inhibitor in idiopathic pulmonary fibrosis. N Engl J Med 2011; 365: 1079-1087

[28] Richeldi L, du Bois RM, Raghu G et al. Efficacy and safety of nintedanib in idiopathic pulmonary fibrosis. N Engl J Med 2014; 370: 2071 - 2082

[29] Richeldi L, du Bois RM, Raghu G et al. Online supplement to: Efficacy and safety of nintedanib in idiopathic pulmonary fibrosis. N Engl J Meddoi:10.1056/NEJMoa1402584

[30] Richeldi L, Cottin V, du Bois RM et al. nintedanib in patients with idiopathic pulmonary fibrosis: Combined evidence from the TOMORROW and INPULSIS(®) trials. Respir Med 2016; 113: 74-79

[31] Costabel U, Inoue Y, Richeldi L et al. Efficacy of nintedanib in Idiopathic Pulmonary Fibrosis across prespecified subgroups in INPULSIS. Am J Respir Crit Care Med 2016; 193: 178-185

[32] Taniguchi H, Xu Z, Azuma A et al. Subgroup analysis of Asian patients in the INPULSIS $®$ trials of nintedanib in idiopathic pulmonary fibrosis. Respirology 2016; 21: $1425-1430$

[33] Wuyts WA, Kolb M, Stowasser $S$ et al. First data on efficacy and safety of nintedanib in patients with idiopathic pulmonary fibrosis and forced vital capacity of $\leq 50 \%$ of Predicted Value. Lung 2016; 194 : $739-743$

[34] Raghu G, Wells AU, Nicholson AG et al. Effect of nintedanib in subgroups of idiopathic pulmonary fibrosis by diagnostic criteria. Am J Respir Crit Care Med 2017; 195: 78-85

[35] Kolb M, Richeldi L, Behr J et al. nintedanib in patients with idiopathic pulmonary fibrosis and preserved lung volume. Thorax 26.09 2016: doi:10.1136/thoraxjnl-2016-208710 pii: thoraxjnl-2016-208710. [Epub ahead of print] PMID: 27672117.

[36] Bonella F, Kreuter M, Hagmeyer L et al. Insights from the German compassionate use program of nintedanib for the treatment of idiopathic pulmonary fibrosis. Respiration 2016; 92: 98-106

[37] Canestaro WJ, Forrester SH, Raghu G et al. Drug treatment of idiopathic pulmonary fibrosis: Systematic review and network meta-analysis. Chest 2016; 149: 756 - 766

[38] Rochwerg B, Neupane B, Zhang Y et al. Treatment of idiopathic pulmonary fibrosis: a network meta-analysis. BMC Med 2016; 14: 18

[39] Rogliani P, Calzetta L, Cavalli F et al. Pirfenidone, nintedanib and $\mathrm{N}$-acetylcysteine for the treatment of idiopathic pulmonary fibrosis: A systematic review and meta-analysis. Pulm Pharmacol Ther 2016; 40: $95-103$

[40] Nakazato H, Oku H, Yamane S et al. A novel antifibrotic agent pirfenidone suppresses tumor necrosis factor-alpha at the translational level. Eur J Pharmacol 2002; 446: 177 - 185

[41] lyer SN, Gurujeyalakshmi G, Giri SN. Effects of pirfenidone on transforming growth factor-beta gene expression at the transcriptional level in bleomycin hamster model of lung fibrosis. J Pharmacol Exp Ther 1999; 291: $367-373$

[42] Iyer SNGG, Gurujeyalakshmi G, Giri SN. Effects of pirfenidone on procollagen gene expression at the transcriptional level in bleomycin hamster model of lung fibrosis. J Pharmacol Exp Ther 1999; 289: $211-218$

[43] Oku H, Shimizu T, Kawabata T et al. Antifibrotic action of pirfenidone and prednisolone: different effects on pulmonary cytokines and growth factors in bleomycin-induced murine pulmonary fibrosis. Eur J Pharmacol 2008; 590: 400-408

[44] Raghu G, Johnson WC, Lockhart D et al. Treatment of idiopathic pulmonary fibrosis with a new antifibrotic agent, pirfenidone: results of a prospective, open-label phase II study. Am J Respir Crit Care Med 1999; 159: 1061 - 1069

[45] Azuma A, Nukiwa T, Tsuboi E et al. Double-blind, placebo-controlled trial of pirfenidone in patients with idiopathic pulmonary fibrosis. Am J Respir Crit Care Med 2005; 171: 1040 - 1047

[46] Taniguchi H, Ebina M, Kondoh Y et al. Pirfenidone Clinical Study Group in Japan. Pirfenidone in idiopathic pulmonary fibrosis. Eur Respir J 2010; 35: $821-829$

[47] Noble PW, Albera C, Bradford WZ et al. CAPACITY Study Group. Pirfenidone in patients with idiopathic pulmonary fibrosis (CAPACITY): two randomised trials. Lancet 2011; 377: 1760-1769

[48] King TE Jr, Bradford WZ, Castro-Bernardini S et al. ASCEND Study Group. A phase 3 trial of pirfenidone in patients with idiopathic pulmonary fibrosis. N Engl J Med 2014; 370: 2083-2092

[49] Noble PW, Albera C, Bradford WZ et al. Pirfenidone for idiopathic pulmonary fibrosis: analysis of pooled data from three multinational phase 3 trials. Eur Respir J 2016; 47: 243-253

[50] Lancaster L, Albera C, Bradford WZ et al. Safety of pirfenidone in patients with idiopathic pulmonary fibrosis: integrated analysis of cumulative data from 5 clinical trials. BMJ open respiratory research 2016; 3: e000105

[51] Albera $C$ et al. Efficacy of pirfenidone in patients with idiopathic pulmonary fibrosis with more preserved lung function. Eur Respir J 09 2016; 48: $843-851$ 
[52] Bonella F, Wessendorf TE, Costabel U. Clinical experience with pirfenidone for the treatment of idiopathic pulmonary fibrosis. Dtsch Med Wochenschr 03 2013; 138: 518-523

[53] Oltmanns U, Kahn N, Palmowski K et al. Pirfenidone in idiopathic pulmonary fibrosis: real-life experience from a German tertiary referral center for interstitial lung diseases. Respiration 2014; 88: 199-207

[54] Loeh B et al. Intraindividual response to treatment with pirfenidone in idiopathic pulmonary fibrosis. Am J Respir Crit Care Med 2015; 191 : $110-113$

[55] Raghu G, Amatto VC, Behr J et al. Comorbidities in idiopathic pulmonary fibrosis patients: a systematic literature review. Eur Respir J 2015; 46: $1113-1130$

[56] Lee JS, Ryu JH, Elicker BM et al. Gastroesophageal reflux therapy is associated with longer survival in patients with idiopathic pulmonary fibrosis. Am J Respir Crit Care Med 2011; 184: 1390

[57] Kreuter M, Ehlers-Tenenbaum S, Palmowski K et al. Impact of Comorbidities on Mortality in Patients with Idiopathic Pulmonary Fibrosis. PLoS One 29.03 2016; 11: e0151425

[58] Allaix ME, Fisichella PM, Noth I et al. The Pulmonary Side of Reflux Disease: from Heartburn to Lung Fibrosis. J Gastrointest Surg 2013; 17: $1526-1535$

[59] Lee JS, Song JW, Wolters PJ et al. Bronchoalveolar lavage pepsin in acute exacerbation of idiopathic pulmonary fibrosis. Eur Respir ] 2012; 39: $352-358$

[60] Raghu G. Idiopathic pulmonary fibrosis: increased survival with "gastroesophageal reflux therapy": fact or fallacy? Am J Respir Crit Care Med 2011; 184: 1330 - 1332

[61] Lee JS, Collard HR, Anstrom KJ et al. Anti-acid treatment and disease progression in idiopathic pulmonary fibrosis: an analysis of data from three randomised controlled trials. Lancet Respir Med 2013; 1: $369-$ 376

[62] Raghu G, Freudenberger TD, Yang S et al. High prevalence of abnormal acid gastro-oesophageal reflux in idiopathic pulmonary fibrosis. Eur Respir J 2006; 27: 136-142

[63] Kreuter M, Wuyts W, Renzoni E et al. Antacid therapy and disease outcomes in idiopathic pulmonary fibrosis: a pooled analysis. Lancet Respir Med 2016; 4: 381-389

[64] Kreuter M, Spagnolo P, Wuyts W et al. Antacid therapy and disease progression in patients with IPF who received pirfenidone. Respiration 2017: doi:10.1159/000468546

[65] Raghu G, Crestani B, Bailes Z et al. Effect of anti-acid medication on reduction in FVC decline with nintedanib. Eur Respir J 2015; 46: (Suppl. 59): OA450

[66] Costabel U, Albera C, Bradford WZ et al. Analysis of lung function and survival in RECAP: an open-label extension study of pirfenidone in patients with idiopathic pulmonary fibrosis. Sarcoidosis Vasc Diffuse Lung Dis 2014; 31: $198-205$

[67] Cottin V, Maher T. Long-termclinical and real-world experiencewith pirfenidone in the treatment of idiopathic pulmonary fibrosis. Eur Respir Rev 2015; 24: 58-64

[68] Okuda R, Hagiwara E, Baba T et al. Safety and efficacy of pirfenidone in idiopathic pulmonary fibrosis in clinical practice. Respir Med 2013; 107: $1431-1437$

[69] Chaudhuri N, Duck A, Frank R et al. Real world experiences: pirfenidone is well tolerated in patients with idiopathic pulmonary fibrosis. Respir Med 2014; 108: 224-226

[70] Arai T, Inoue Y, Sasaki Y et al. Predictors of the clinical effects of pirfenidone on idiopathic pulmonary fibrosis. Respir Investig 2014; 52 : $136-143.31$

[71] Taguchi Y, Ebina M, Hashimoto S et al. Efficacy of pirfenidone and disease severity of idiopathic pulmonary fibrosis: Extended analysis of phase III trial in Japan. Respir Investig 2015; 53: 279-87
[72] King CS, Nathan SD. Practical considerations in the pharmacologic treatment of idiopathic pulmonary fibrosis. Curr Opin Pulm Med 2015; 21: 479-89

[73] du Bois RM, Weycker D, Albera C et al. Forced vital capacity in patients with idiopathic pulmonary fibrosis test properties and minimal clinically important difference. Am J Respir Crit Care Med 2011; 184: $1382-1389$

[74] Behr J, Bonella F, Bonnet R et al. Position Paper: Significance of the Forced Vital Capacity in Idiopathic Pulmonary Fibrosis. Pneumologie 2015; 69: 455 - 458 Epub 2015 Jul 30. German. PubMed PMID: 26227628

[75] Nathan SD et al. Effect of continued treatment with pirfenidone following clinically meaningful declines in forced vital capacity: analysis of data from three phase 3 trials in patients with idiopathic pulmonary fibrosis. Thorax 2016; 71: 429-435 Epub 2016 Mar 11. PubMed PMID: 26968970; PubMed Central PMCID: PMC4862066.

[76] Richeldi L, Azuma A, Selman M et al. Twenty-four week decline in forced vital capacity predicts mortality at week 52 in the INPULSIS ${ }^{\circledR}$ trials. Eur Respir J 2016: OA1814

[77] Milger K, Kneidinger $N$, Neurohr $C$ et al. Switching to nintedanib after discontinuation of pirfenidone dueto adverse events in IPF. Eur Respir | 2015; 46: 1217-1221

[78] Wuyts WA, Antoniou KM, Borensztajn K et al. Combination therapy: the future of management for idiopathic pulmonary fibrosis? Lancet Respir Med 2014; 2: 933 - 942

[79] Behr J, Bendstrup E, Crestani B et al. Safety and tolerability of acetylcysteine and pirfenidone combination therapy in idiopathic pulmonary fibrosis: a randomised, double-blind, placebo-controlled, phase 2 trial. Lancet Respir Med 2016; 4: 445-453

[80] Ogura T, Taniguchi H, Azuma A et al. Safety and pharmacokinetics of nintedanib and pirfenidone in idiopathic pulmonary fibrosis. Eur Respir J 2015; 45: $1382-1392$

[81] Raghu G, Collard HR, Egan JJ et al. ATS/ERS/JRS/ALAT Committee on Idiopathic Pulmonary Fibrosis. An official ATS/ERS/JRS/ALAT statement: idiopathic pulmonary fibrosis: evidence-based guidelines for diagnosis and management. Am J Respir Crit Care Med 2011; 183: $788-824$

[82] Lettieri C], Veerappan GR, Helman DL et al. Outcomes and safety of surgical lung biopsy for interstitial lung disease. Chest 2005; 127: $1600-1605$

[83] Park JH, Kim DK, Kim DS et al. Mortality and risk factors for surgical lung biopsy in patients with idiopathic pulmonary fibrosis. Eur J Cardiothorac Surg 2007; 31: 1115-1119

[84] Hutchinson JP, Fogarty AW, McKeever TM et al. In-Hospital Mortality after Surgical Lung Biopsy for Interstitial Lung Disease in the United States. 2000 to 2011. Am J Respir Crit Care Med 2016; 193: 1161 1167

[85] Casoni GL, Tomassetti S, Cavazza A et al. Cryobiopsy in the diagnosis of fibrotic interstitial lung diseases. PLoS One 2014; 9: 02 e86716 doi:10.1371/journal.pone.0086716.eCollection2014

[86] Tomassetti S, Wells AU, Costabel U et al. Bronchoscopic lung cryobiopsy increases diagnostic confidence in the multidisciplinary diagnosis of idiopathic pulmonary fibrosis. Am J Respir Crit Care Med 2016; 193: $745-752$

[87] Ravaglia C, Bonifazi M, Wells AU et al. Safety and diagnostic yield of transbronchial lung cryobiopsy in diffuse parenchymal lung diseases: A comparative study versus video-assisted thoracoscopic lung biopsy and a systematic review of the literature. Respiration 2016; 91: 215227

[88] Poletti V, Ravaglia C, Tomassetti S. Transbronchial cryobiopsy in diffuse parenchymal lung diseases. Curr Opin Pulm Med 2016; 22: $289-$ 296

[89] Poletti V, Ravaglia C, Gurioli C et al. Invasive diagnostic techniques in idiopathic interstitial pneumonias. Respirology 2016; 21: 44-50 